\title{
Clinical potential of TCF21 methylation in the diagnosis of renal cell carcinoma
}

\author{
JUN XIN $^{1 *}$, RONG XU $^{2 *}$, SHAOKUN LIN $^{1}$, MINGHUA XIN $^{1}$, WENJIE CAI ${ }^{1}$, JIN ZHOU ${ }^{1}$, \\ CHANGDE FU ${ }^{1}$, GUANGFU ZHEN ${ }^{3}$, JINJIN LAI ${ }^{1}$, YUE $\mathrm{LI}^{4}$ and PENGFENG ZHANG ${ }^{4}$ \\ ${ }^{1}$ Department of Urology, The First Hospital of Quanzhou Affiliated Fujian Medical University, \\ Quanzhou, Fujian 362000; ${ }^{2}$ Department of Pharmacy, Quanzhou Medical College, Quanzhou, Fujian 362011; \\ ${ }^{3}$ Department of Urology, General Hospital of the People's Liberation Army, Beijing 100853; \\ ${ }^{4}$ Xiamen Xinchuang Bio-Technology Co. Ltd, Xiamen, Fujian 361021, P.R. China
}

Received January 29, 2015; Accepted February 24, 2016

DOI: $10.3892 / \mathrm{ol} .2016 .4748$

\begin{abstract}
The aim of the present study was to investigate the clinical potential of transcription factor $(T C F) 21$ methylation in the diagnosis of renal cell carcinoma (RCC). TCF21 methylation levels were quantified in renal tissues ( 55 cases of RCC tissue and 22 cases of normal tissue) and urine samples (33 cases of urine samples with RCC and 15 cases of normal urine samples) using pyrosequencing. Spearman's rank correlation coefficient was used to investigate the correlation between TCF21 methylation levels and clinical parameters (gender, age, smoking history, Fuhrman grade and clinical stage). The receiver operating characteristic (ROC) curve was utilized to evaluate the accuracy of predictive diagnosis of RCC. TCF21 methylation levels were significantly increased in RCC samples compared with normal renal tissues and urine samples. The Spearman's correlation analysis revealed that the TCF21 methylation level was positively associated with age $(\mathrm{P}=0.002)$, smoking $(\mathrm{P}=0.017)$ and Fuhrman grade $(\mathrm{P}=0.045)$ in $\mathrm{RCC}$ tissues and was positively associated with tumor size $(\mathrm{P}<0.001)$, Fuhrman grade $(\mathrm{P}=0.017)$ and clinical stage $(\mathrm{P}=0.017)$ in urine samples. ROC curves revealed that the cut-off value, sensitivity and specificity were $23.61,89.00$ and $61.90 \%$, respectively in tissue samples, and $26.84,79$ and $100 \%$, respectively in urine samples. Furthermore, there were significant differences in the area under the curve between the tissue and urine samples $(\mathrm{P}=0.004)$. The results of the present study indicate that TCF 21 may be used as a biomarker
\end{abstract}

Correspondence to: Dr Jun Xin, Department of Urology, The First Hospital of Quanzhou Affiliated Fujian Medical University, 248-252 East Street, Quanzhou, Fujian 362000, P.R. China E-mail: junxinxj@163.com

*Contributed equally

Key words: transcription factor 21, methylation level, renal cell carcinoma, pyrosequencing for diagnosing RCC, and TCF21 methylation levels in urine samples may be a useful means of diagnosing RCC.

\section{Introduction}

Renal cell carcinoma (RCC) accounts for $\sim 3 \%$ of malignant tumors in adults and $>90 \%$ of neoplasms originating from the kidney $(1,2)$. It has been reported that RCC is the ninth most common cancer worldwide, with approximately 337,860 new cases diagnosed in 2012 (3). The incidence of RCC differs geographically and the highest incidence occurs in developed countries (1). In addition, it possesses the highest mortality rate of the genitourinary cancers and up to $30 \%$ of patients exhibit metastases at the time of initial diagnosis (4). The increasing incidence and mortality predicts that $\mathrm{RCC}$ will continue to be a significant health burden in the future (5). Although a minority of RCC patients have a high risk of recurrence, $\mathrm{RCC}$ is largely curable by surgery if detected early (6). However, detection of cancerous cells at early stages is challenging due to the lack of early symptoms and incorrect distinction between benign and malignant masses through imaging or needle biopsies (7). Therefore, investigation of innovative noninvasive approaches allowing for early detection of RCC has been performed (8).

Previously, promoter hypermethylation involving DNA methylation of $\mathrm{CpG}$ islands has been considered to be a critical mechanism during cancer development (9-11). Aberrant DNA methylation in the regulatory region of cancer-associated genes has now been established as an alternative mechanism to heritably silence gene transcription $(12,13)$. Transcription factor 21 (TCF21) is a validated target of aberrant promoter hypermethylation in cancer, and is crucial for the differentiation of epithelial cells adjacent to the mesenchyme (14). TCF 21 is a member of the basic helix-loop-helix transcription factor family and has a significant role in the regulation of cell differentiation and cell fate decisions during development of the lung, kidney and spleen (15). Furthermore, it has been considered to be a candidate tumor suppressor at 6q23-q24 that is epigenetically inactivated in several types of human cancer (16-18). A previous study reported that the methylation level of TCF21 was markedly increased in patients with clear cell RCC (ccRCC) and was additionally an independent 
prognostic factor for poor survival (16). Costa et al (19) identified that TCF21 was part of an innovative panel of biomarkers for simultaneous detection of bladder cancer, RCC and prostate cancer; however, to the best of our knoweldege, correlations between TCF21 methylation levels and clinical parameters have rarely been reported since then.

In the present study, the clinical potential of TCF21 methylation in the diagnosis of RCC was investigated and the correlations between TCF 21 methylation levels and certain clinical parameters in renal tissues and urine samples were analyzed. The results of the present study indicate that detection of TCF 21 methylation may provide an effective novel method for diagnosing RCC.

\section{Materials and methods}

Patient and tumor sample collection. The present study was approved by the ethics committee of First Hospital of Quanzhou Affiliated Fujian Medical University (Quanzhou, China)(batch number, 20131016) and written informed consent was obtained from all participants. Between February 2011 and December 2013, 55 consecutive patients with RCC, including 30 men and 25 women, who had received treatment at the First Hospital of Quanzhou Affiliated Fujian Medical University were enrolled in the present study. Tumor samples were obtained from these patients subsequent to resection. Samples were instantly snap-frozen, stored at $-80^{\circ} \mathrm{C}$ in liquid nitrogen and cut in a cryostat (Reichert Jung Cryocut 1800; Leica Microsystems, Inc., Buffalo Grove, IL, USA) for subsequent DNA extraction. The normal renal cell tissue samples from 22 RCC-free individuals were used as controls.

Urine sample collection and processing. First morning voided urine samples (1 sample per patient; 20-50 ml) were collected from 33 patients (28 males and 5 females) with RCC, who had been diagnosed and treated between February 2011 and December 2013 in the Department of Urology of First Hospital of Quanzhou Affiliated Fujian Medical University. Healthy individuals with no history of occupational exposure to carcinogens or personal/familial history of cancer were selected as the control group ( $n=15 ; 10$ males and 5 females). Written informed consent was obtained from all subjects prior to enrolling into the study. The storage and processing procedures for urine samples were standardized. Briefly, samples were centrifuged at $1,776 \mathrm{x}$ g for $10 \mathrm{~min}$, and the pelleted urine sediment was rinsed with phosphate-buffered saline (Shanghai Qifa Biotechnology Co., Ltd., Shanghai, China) 2 times for 10 min each and stored at $-80^{\circ} \mathrm{C}$ until required.

Isolation of nucleic acids and bisulfite treatment. DNA was extracted from the frozen tissue and urine samples using the AllPrep DNA Mini kit (Qiagen, Inc., Valencia, CA, USA) according to the manufacturer's protocol. The concentration and purity of DNA were assessed by determining the $\mathrm{OD}_{260} / \mathrm{OD}_{280}$ ratio using a Nanodrop 1000 spectrophotometer (Thermo Fisher Scientific, Inc., Waltham, MA, USA). DNA was treated by bisulfite using an EZ-96 DNA Methylation-Gold ${ }^{\mathrm{TM}}$ kit (Zymo Research, Irvine, CA, USA) according to the manufacturer's protocol, as well as the previously described protocol (20), and stored at $-80^{\circ} \mathrm{C}$ until use.
Quantitative pyrosequencing methylation analysis. In order to detect the methylation level of the TCF 21 gene in urine and tissue samples, a total of $22 \mathrm{CpG}$ loci of 3 fragments in the TCF 21 gene were selected for methylation. Polymerase chain reaction (PCR) and TCF 21 sequencing primers were designed with the PyroMark Assay Design 2.0 software (Qiagen, Inc.). The primers were as follows: Forward, TTAGTTAGGAGG GGAAGTAGGTTT; reverse, ACACCCAAAACAAAA TAATCTTAAATCT; and sequencing, GGGGAAGTAGGT TTAG for TCF21 1; forward, AGTGTTTTAGGGGTTGTA GTTGTAGTTTA; reverse, CACACCCCCACTCCCAAC; and sequencing, GTTGTAGTTGTAGTTTAGG TCF21 2; and forward, GGTGGAAGGTTTAGAAAGAGTTA; reverse, ACCACCTTCTCCCAACTA; and sequencing, GGAAGG TTTAGAAAGAGTTAA TCF21 3. PCR was performed with the HotStarTaq Master Mix kit (Qiagen, Inc.) according to the manufacturer's protocol, with $1 \mu \mathrm{l}$ of bisulfate-converted DNA. PCR amplification was performed as follows: Denaturation at $95^{\circ} \mathrm{C}$ for $5 \mathrm{~min}$, followed by 45 cycles at $95^{\circ} \mathrm{C}$ for $1 \mathrm{~min}$, annealing at $36^{\circ} \mathrm{C}$ for $1 \mathrm{~min}$ and a final extension at $72^{\circ} \mathrm{C}$ for $5 \mathrm{~min}$. Following PCR amplification, pyrosequencing was performed using a PyroMark Gold Q96 SQA Reagents kit (Qiagen, Inc.) and a PSQ96 HS DNA analyzing system (Qiagen, Inc.) according to the manufacturer's protocol. Pyro Q-CpG software version 1.0.9 (Qiagen, Inc.) was used to calculate the percentage of methylation w, as follows: Methylation $(\%)=$ methylated cytosine $/$ total cytosine $\mathrm{x} 100$.

Statistical analysis. Data are expressed as the mean \pm standard deviation. Statistical analyses were performed using SPSS for Windows, version 20 (IBM SPSS, Armonk, NY, USA). Pairwise comparison utilized the Mann-Whitney U test. Spearman's rank correlation was employed in order to examine the association between multiple clinical parameters. A receiver operating characteristic (ROC) curve was constructed in order to evaluate the accuracy of the predictive model. $\mathrm{P}<0.05$ was considered to indicate a statistically significant difference.

\section{Results}

Methylation level of the TCF21 gene. The data analysis of the first fragment of TCF 21 is presented in Fig. 1. A total of $22 \mathrm{CpG}$ sites of 3 fragments in the TCF 21 gene promoter in each sample were detected. The results revealed that there were significant differences in the methylation level of the first fragment in the cancer and normal tissues at 9 sites (sites 8-11, 14-16, 18-19). In addition, TCF21 methylation levels were significantly increased in cancerous renal tissue and urine samples compared with normal renal tissue and urine samples.

Clinicopathological analysis of TCF21 methylation level in RCC tissue. An analysis of TCF 21 methylation levels in RCC tissues in relation to various clinical parameters is presented in Fig. 2. The results of the analysis demonstrated that TCF21 methylation levels were increased in male patients, patients aged $\geq 50$ years, smokers, patients with tumor size $\geq 7 \mathrm{~cm}$ and clinical stage III or IV (21) compared with female patients, patients aged $<50$ years, nonsmokers, patients with tumor size $<7 \mathrm{~cm}$ and Fuhrman grade I or II (22). The Spearman's correlation coefficient between TCF 21 methylation levels and clinical 
Table I. Correlation between transcription factor 21 methylation levels and clinical parameters in renal cell carcinoma tissue.

\begin{tabular}{lcc}
\hline Clinical parameter & P-value & $\mathrm{r}$ \\
\hline Gender & 0.227 & 0.166 \\
Age & 0.002 & 0.403 \\
Tumor size & 0.423 & 0.11 \\
Smoking & 0.017 & 0.321 \\
Fuhrman grade & 0.045 & 0.271 \\
Clinical stage & 0.057 & 0.258 \\
\hline
\end{tabular}

Table II. Correlation between transcription factor 21 methylation levels and clinical parameters in urine samples with renal cell carcinoma.

\begin{tabular}{lcc}
\hline Clinical parameter & P-value & $\mathrm{r}$ \\
\hline Gender & 0.43 & 0.142 \\
Age & 0.713 & 0.067 \\
Tumor size & 0.000 & 0.622 \\
Smoking & 0.204 & 0.227 \\
Fuhrman grade & 0.010 & 0.441 \\
Clinical stage & 0.017 & 0.411 \\
\hline
\end{tabular}

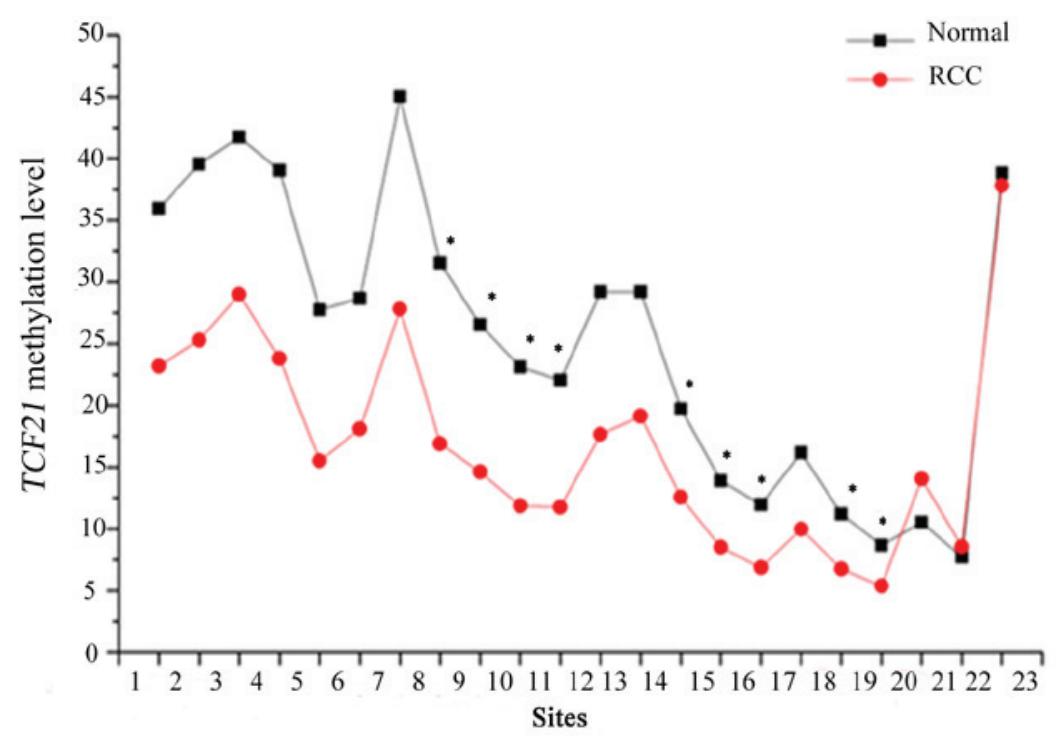

Figure 1. Data analysis of the first fragment of TCF21. The results revealed that there were significant differences between the cancer and normal tissues at 9 methylation sites (sites 8-11, 14-16 and 18-19) of the first fragment. " $\mathrm{P}<0.05$ normal vs. control. TCF21, transcription factor 21; RCC, renal cell carcinoma.

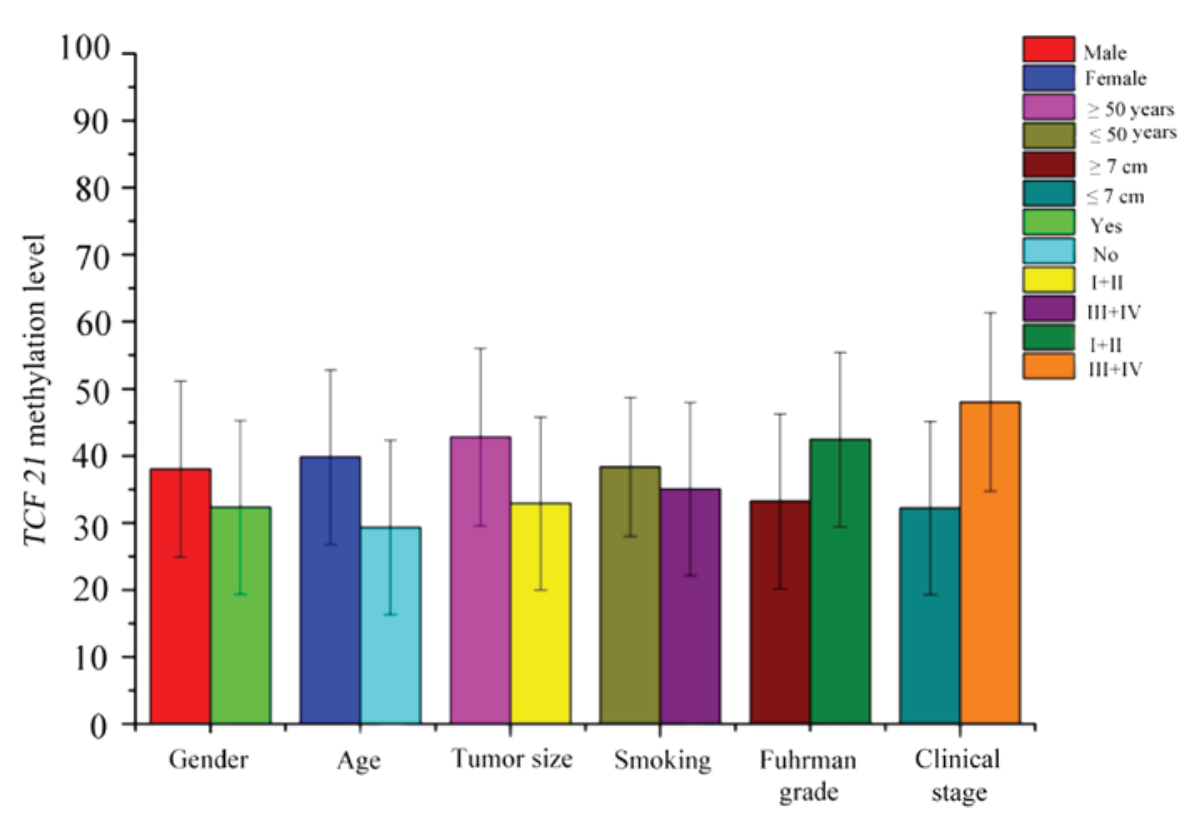

Figure 2. A comparison between $T C F 21$ methylation levels in RCC tissue and various clinical parameters. The results of the analysis demonstrated that $T C F 21$ methylation levels were increased in male patients, patients aged $\geq 50$ years, smokers, patients with tumor size $\geq 7 \mathrm{~cm}$ and clinical stage III or IV. TCF 21 , transcription factor 21 ; RCC, renal cell carcinoma. 


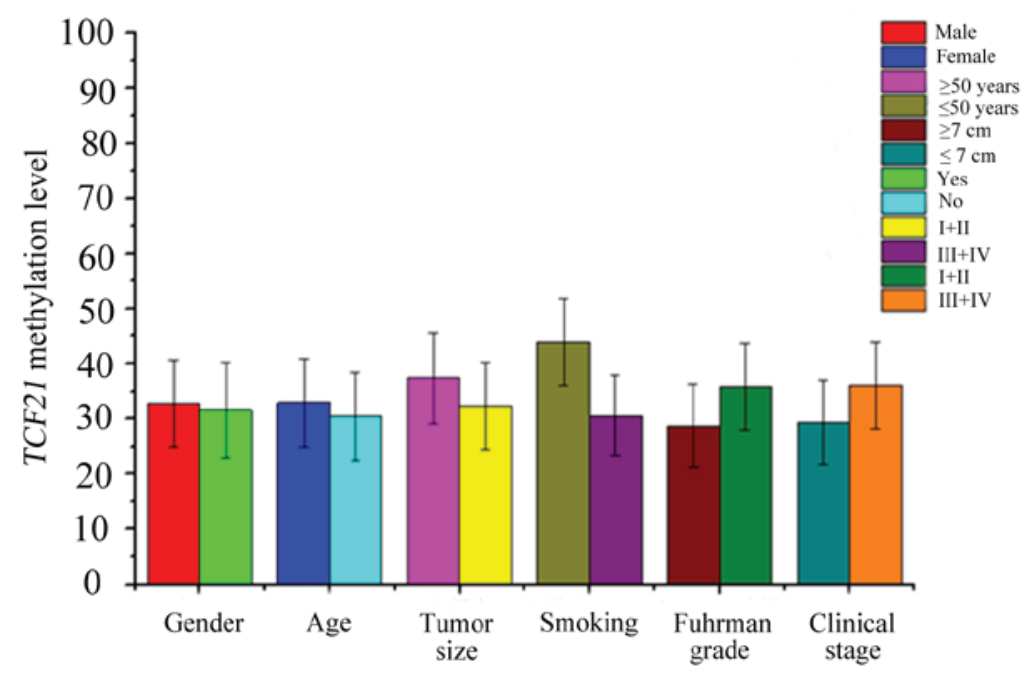

Figure 3. A comparison between TCF21 methylation levels in urine samples with RCC and various clinical parameters. TCF21 methylation levels were increased in male patients, patients aged $\geq 50$ years, smokers, patients with tumor size $\geq 7 \mathrm{~cm}$ and clinical stage III or IV. TCF21, transcription factor 21; RCC, renal cell carcinoma.

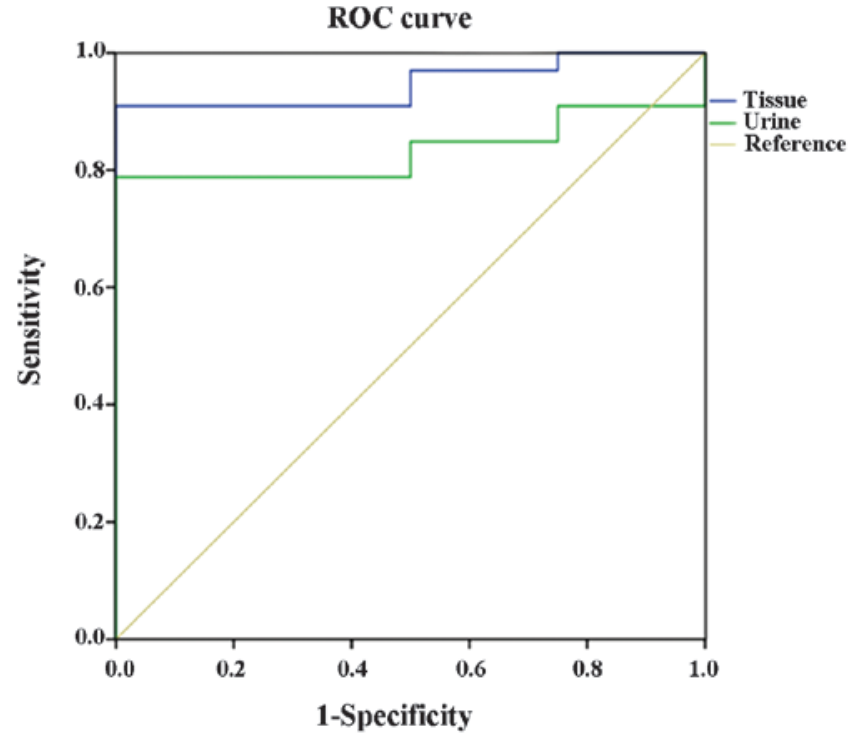

Figure 4. The ROC curve of TCF21 methylation level in RCC tissue and urine samples. The diagnostic validity of the TCF21 methylation level in RCC tissues was increased compared with RCC urine samples. ROC, receiver operating characteristic; TCF21, transcription factor 21 ; RCC, renal cell carcinoma.

parameters is summarized in Table I. The results demonstrated that TCF21 methylation level was positively associated with age ( $\mathrm{r}=0.403 ; \mathrm{P}=0.002)$, smoking history $(\mathrm{r}=0.321 ; \mathrm{P}=0.017)$ and Fuhrman grade $(r=0.271 ; P=0.045)$. However, there were no significant differences for gender $(r=0.166 ; \mathrm{P}=0.227)$, tumor size $(r=0.110 ; \mathrm{P}=0.423)$ and clinical stage $(\mathrm{r}=0.258 ; \mathrm{P}=0.057)$.

Clinicopathological analysis of TCF21 methylation level in urine samples with RCC. A comparison between TCF21 methylation levels in urine samples with RCC and various clinical parameters is presented in Fig. 3. Similarly, TCF 21 methylation levels of male patients, patients aged $\geq 50$ years, smokers, patients with tumor size $\geq 7 \mathrm{~cm}$ and clinical stage III or IV were increased compared with female patients, patients aged $<50$ years, nonsmokers, patients with tumor size $<7 \mathrm{~cm}$ and Fuhrman grade I or II. Spearman's correlation analysis revealed that the TCF21 methylation level was positively associated with tumor size $(\mathrm{r}=0.622 ; \mathrm{P}<0.001)$, Fuhrman grade $(\mathrm{r}=0.411 ; \mathrm{P}=0.017)$ and clinical stage $(\mathrm{r}=0.411 ; \mathrm{P}=0.017)$. However, there were no significant differences for gender $(\mathrm{r}=0.142 ; \mathrm{P}=0.430)$, age $(\mathrm{r}=0.067 ; \mathrm{P}=0.713)$ and smoking history ( $\mathrm{r}=0.441 ; \mathrm{P}=0.010$; Table II).

ROC curve of TCF 21 methylation level in RCC tissue and urine samples. The ROC curve of TCF 21 methylation level in RCC tissue and urine samples is presented in Fig. 4. In the ROC curve analysis of TCF 21 methylation level in RCC tissue, the cut-off value was $23.61 \%$ and the sensitivity and specificity were 89.00 and $61.90 \%$, respectively for predicting RCC. The ROC curve analysis of TCF 21 methylation level in urine samples with RCC demonstrated a cut-off value of $26.84 \%$ and the sensitivity and specificity were 79.00 and $100.00 \%$, respectively for predicting RCC. Furthermore, there were significant differences in the area under the curve between the tissue and urine samples $(\mathrm{P}=0.004)$, which may indicate that the diagnostic validity of the TCF21 methylation level in RCC tissue was increased compared with urine samples with RCC.

\section{Discussion}

In the present study, the clinical potential of the observation of TCF 21 methylation for the diagnosis of RCC was investigated in tissue and urine samples. The results of the present study demonstrated that TCF 21 methylation levels were significantly increased in RCC tissue and urine samples compared with normal tissue and urine samples. Furthermore, TCF21 methylation was additionally positively associated with age, smoking history and Fuhrman grade in RCC tissues and tumor size, Fuhrman grade and clinical stage in urine samples. In addition, the sensitivity was significantly increased in RCC tissue samples compared with urine samples. It was concluded that TCF21 may be a useful biomarker for diagnosing RCC, 
and TCF21 methylation levels in urine samples may be a novel method of diagnosing RCC.

It is a challenging task to screen for the early stages of RCC. RCC tends to be clinically asymptomatic during its earliest stages; therefore, approximately $20-30 \%$ of cases are diagnosed at a locally advanced stage or with metastasis (23). Although noninvasive imaging (including computed tomography and ultrasonography) has been widely used in the detection of RCC, diagnostic challenges are arising due to problems with accurate discrimination of benign from malignant masses and accurate categorization (24). Thus, the development of more efficient and accurate detection of RCC at early stages is imperative. The role of epigenetic alterations and gene promoter hypermethylation in the early diagnosis of cancer is receiving increasing attention (7,25-28). An emerging class of cancer biomarkers, including prostaglandin-endoperoxide synthase 2, Ras association domain family 1 isoform $A$, retinoic acid receptor $\beta$ and Kelch-like family member 35 , has been previously reported to be methylated in RCC, with a sensitivity of $31-77 \%$ and specificity of $75-91 \%$ (29-32). In addition, Costa et al (19) demonstrated that protocadherin-17 and TCF 21 aberrant promoter methylation may have a critical role in urological cancers. Furthermore, Ye et al (16) indicated that TCF21 may be a predictive biomarker of poor prognosis in patients with ccRCC. However, correlations between TCF21 methylation levels and clinical parameters were not reported in this previous study (16).

TCF 21 is a newly recognized target of aberrant promoter hypermethylation in malignancies, which encodes a basic helix-loop-helix transcription factor $(33,34)$. It is involved in mesenchymal-epithelial cell transition and controls cell fate determination and tissue differentiation in the embryo (35). The present study investigated the clinical potential of TCF21 methylation in the diagnosis of RCC, and additionally evaluated the correlations between TCF 21 methylation levels and certain clinical parameters in renal tissues and urine samples. The results of the present study revealed that TCF 21 methylation levels were significantly increased in RCC samples compared with those of normal renal tissues or urine samples, which was in line with the findings of previous studies $(16,19)$. The Spearman's correlation coefficient revealed that the TCF21 methylation level was positively associated with age, smoking history and Fuhrman grade in RCC tissues and associated with tumor size, Fuhrman grade and clinical stage in urine samples. The above results indicated that the TCF 21 methylation level was associated with the degree of malignancy and differentiation of RCC; the higher the level of TCF21 methylation, the higher the degree of RCC malignancy. In addition, age and smoking history were associated with RCC; however, the mechanisms underlying these associations remain to be elucidated. The present study hypothesized that aging and smoking may act on the aberrant methylation of TCF 21 .

ROC curves revealed the cut-off value, sensitivity and specificity for predicting RCC were 23.61, 89.00 and $61.90 \%$, respectively in tissue samples and were 26.84, 79.00 and $100.00 \%$, respectively in urine samples. Significant differences were identified in the area under the curve between the tissue and urine samples. These results are similar to a previous finding which demonstrated a significant decrease in sensitivity in urine sample (36). One of the primary reasons for these observed results may be due to the varying amount of neoplastic cells in tissues and urine samples. Therefore, the results might be improved by increase the volume of tested urine samples, because it seems to increase the content of DNA from RCC tumors. Despite these marked differences in the area under the curve, TCF 21 methylation levels in urine samples may be considered to be a novel and useful method of diagnosing RCC.

In conclusion, the results of the present study demonstrated that TCF21 methylation levels were significantly increased in RCC tissue and urine samples compared with normal tissue and urine samples. TCF21 may be utilized as a biomarker for the diagnosis of RCC and the detection of methylation levels in RCC urine samples may be a novel and efficient method of diagnosing RCC, due to the noninvasive nature of this method

\section{Acknowledgements}

The present study was supported by Quanzhou Science and Technology Project (grant no. 2013Z52; Quanzhou, China) and Quanzhou Medical College Science and Technology Project (grant no. XJ1305; Quanzhou, China).

\section{References}

1. Ljungberg B, Campbell SC, Choi HY, Jacqmin D, Lee JE, Weikert S and Kiemeney LA: The epidemiology of renal cell carcinoma. Eur Urol 60: 615-621, 2011.

2. Sachdeva K, Curti B and Bagi JRP: Renal cell carcinoma. http:// emedicine.medscape.com/article/281340-overview. Accessed May 17, 2016

3. Maher ER: Genomics and epigenomics of renal cell carcinoma. Semin Cancer Biol 23: 10-17, 2013.

4. Janzen NK, Kim HL, Figlin RA and Belldegrun AS: Surveillance after radical or partial nephrectomy for localized renal cell carcinoma and management of recurrent disease. Urol Clin North Am 30: 843-852, 2003.

5. Ferlay J, Shin HR, Bray F, Forman D, Mathers C and Parkin DM: Estimates of worldwide burden of cancer in 2008: GLOBOCAN 2008. Int J Cancer 127: 2893-2917, 2010.

6. Smith SJ, Bosniak MA, Megibow AJ, Hulnick DH, Horii SC, and Raghavendra BN: Renal cell carcinoma: Earlier discovery and increased detection. Radiology 170: 699-703, 1989.

7. Cairns P: Gene methylation and early detection of genitourinary cancer: The road ahead. Nat Rev Cancer 7: 531-543, 2007.

8. Scélo $\mathrm{G}$ and Brennan P: The epidemiology of bladder and kidney cancer. Nat Clin Pract Urol 4: 205-217, 2007.

9. Park SY, Kwon HJ, Lee HE, Ryu HS, Kim SW, Kim JH, Kim IA, Jung N, Cho NY and Kang GH: Promoter CpG island hypermethylation during breast cancer progression. Virchows Arch 458: 73-84, 2011.

10. Park JY: Promoter hypermethylation in prostate cancer. Cancer Control 17: 245-255, 2010.

11. Akhavan-Niaki H and Samadani AA: DNA methylation and cancer development: Molecular mechanism. Cell Biochem Biophys 67: 501-513, 2013.

12. Vucic EA, Brown CJ and Lam WL: Epigenetics of cancer progression. Pharmacogenomics 9: 215-234, 2008.

13. Duffy M, Napieralski R, Martens JW, Span PN, Spyratos F, Sweep FC, Brunner N, Foekens JA and Schmitt M; EORTC PathoBiology Group: Methylated genes as new cancer biomarkers. Eur J Cancer 45: 335-346, 2009.

14. Herman JG and Baylin SB: Gene silencing in cancer in association with promoter hypermethylation. N Engl J Med 349: 2042-2054, 2003.

15. Quaggin SE, Schwartz L, Cui S, Igarashi P, Deimling J, Post M and Rossant J: The basic-helix-loop-helix protein podl is critically important for kidney and lung organogenesis. Development 126: 5771-5783, 1999.

16. Ye YW, Jiang ZM, Li WH, Li ZS, Han YH, Sun L, Wang Y, Xie J, Liu YC, Zhao J, et al: Down-regulation of TCF21 is associated with poor survival in clear cell renal cell carcinoma. Neoplasma 59: 599-605, 2012. 
17. Arab K, Smith LT, Gast A, Weichenhan D, Huang JP, Claus R, Hielscher T, Espinosa AV, Ringel MD, Morrison CD, et al: Epigenetic deregulation of TCF21 inhibits metastasis suppressor KISS1 in metastatic melanoma. Carcinogenesis 32: 1467-1473, 2011.

18. Richards KL, Zhang B, Sun M, Dong W, Churchill J, Bachinski LL, Wilson CD, Baggerly KA, Yin G, Hayes DN, et al: Methylation of the candidate biomarker TCF21 is very frequent across a spectrum of early-stage nonsmall cell lung cancers. Cancer 117: 606-617, 2011.

19. Costa VL, Henrique R, Danielsen SA, Eknaes M, Patrício P, Morais A, Oliveira J, Lothe RA, Teixeira MR, Lind GE and Jerónimo C: TCF21 and PCDH17 methylation: An innovative panel of biomarkers for a simultaneous detection of urological cancers. Epigenetics 6: 1120-1130, 2011.

20. Shaw RJ, Liloglou T, Rogers SN, Brown JS, Vaughan ED, Lowe D, Field JK and Risk JM: Promoter methylation of P16, RARbeta, E-cadherin, cyclin A1 and cytoglobin in oral cancer: Quantitative evaluation using pyrosequencing. Br J Cancer 94: 561-568, 2006.

21. Zisman A, Pantuck AJ, Dorey F, Said JW, Shvarts O, Quintana D, Gitlitz BJ, deKernion JB, Figlin RA and Belldegrun AS: Improved prognostication of renal cell carcinoma using an integrated staging system. J Clin Oncol 19: 1649-1657, 2001.

22. Lang H, Lindner V, de Fromont M, Molinié V, Letourneux H, Meyer N, Martin M and Jacqmin D: Multicenter determination of optimal interobserver agreement using the Fuhrman grading system for renal cell carcinoma. Cancer 103: 625-629, 2005.

23. Lam JS, Leppert JT, Belldegrun AS and Figlin RA: Novel approaches in the therapy of metastatic renal cell carcinoma. World J Urol 23: 202-212, 2005.

24. Yang XJ, Sugimura J, Schafernak KT, Tretiakova MS, Han M, Vogelzang NJ, Furge K and Teh BT: Classification of renal neoplasms based on molecular signatures. J Urol 175: 2302-2306, 2006.

25. Jerónimo $C$, Henrique $R$ and Sidransky D: Uses of DNA methylation in cancer diagnosis and risk assessment. In: DNA Methylation: Approaches, Methods and Applications. Esteller M (ed). 1st edition. CRC Press, Boca Raton, FL, pp 11-26, 2004.

26. Henrique R, Luís AS and Jerónimo C: The epigenetics of renal cell tumors: From biology to biomarkers. Front Genet 3: 94, 2012.
27. Jerónimo $\mathrm{C}$ and Henrique R: Epigenetic biomarkers in urological tumors: A systematic review. Cancer Lett 342: 264-274, 2014.

28. Morris MR and Maher ER: Epigenetics of renal cell carcinoma: The path towards new diagnostics and therapeutics. Genome Med 2: 59, 2010.

29. Costa VL, Henrique R, Ribeiro FR, Pinto M, Oliveira J, Lobo F, Teixeira MR and Jerónimo C: Quantitative promoter methylation analysis of multiple cancer-related genes in renal cell tumors. BMC Cancer 7: 133, 2007.

30. Morris MR, Ricketts C, Gentle D, Abdulrahman M, Clarke N, Brown M, Kishida T, Yao M, Latif F and Maher ER: Identification of candidate tumour suppressor genes frequently methylated in renal cell carcinoma. Oncogene 29: 2104-2117, 2010.

31. Hoque MO, Begum S, Topaloglu O, Jeronimo C, Mambo E, Westra WH, Califano JA and Sidransky D: Quantitative detection of promoter hypermethylation of multiple genes in the tumor, urine and serum DNA of patients with renal cancer. Cancer Res 64: 5511-5517, 2004.

32. Morris MR, Ricketts CJ, Gentle D, McRonald F, Carli N, Khalili H, Brown M, Kishida T, Yao M, Banks RE, et al: Genome-wide methylation analysis identifies epigenetically inactivated candidate tumour suppressor genes in renal cell carcinoma. Oncogene 30: 1390-1401, 2011.

33. Smith LT, Lin M, Brena RM, Lang JC, Schuller DE, Otterson GA, Morrison CD, Smiraglia DJ and Plass C: Epigenetic regulation of the tumor suppressor gene TCF21 on 6q23-q24 in lung and head and neck cancer. Proc Natl Acad Sci USA 103: 982-987, 2006.

34. Quaggin SE, Vanden Heuvel GB and Igarashi P: Pod-1, a mesoderm-specific basic-helix-loop-helix protein expressed in mesenchymal and glomerular epithelial cells in the developing kidney. Mech Dev 71: 37-48, 1998.

35. Quaggin SE, Schwartz L, Cui S, Igarashi P, Deimling J, Post M and Rossant J: The basic-helix-loop-helix protein pod1 is critically important for kidney and lung organogenesis. Development 126: 5771-5783, 1999.

36. Costa VL, Henrique R, Danielsen SA, Eknaes M, Patricio P, Morais A, Olieira J, Lothe RA, Teixeira MR, Lind GE and Jerónimo C: TCF21 and PCDH17 methylation: An innovative panel of biomarkers for a simultaneous detection of urological cancers. Epigenetics 6: 1120-1130, 2011. 